\title{
PTGS1, PTGS2, ALOX5, ALOX12, ALOX15, and FLAP SNPs: interaction with fatty acids in colon cancer and rectal cancer
}

\author{
Nina Habermann • Cornelia M. Ulrich • Abbie Lundgreen • Karen W. Makar • \\ Elizabeth M. Poole • Bette Caan · Richard Kulmacz • John Whitton • \\ Rachel Galbraith $\cdot$ John D. Potter $\cdot$ Martha L. Slattery
}

Received: 3 February 2012/ Accepted: 18 May 2012/Published online: 8 June 2012

(C) Springer-Verlag 2012

\begin{abstract}
Dietary polyunsaturated fatty acids (PUFAs) can be converted to prostaglandins and leukotrienes. Oxygenation of omega-6 PUFAs generally results in the production of pro-inflammatory mediators, whereas oxygenated products of omega-3 (n-3) PUFAs generally have lower inflammatory activity. We hypothesize that elevated n-3 PUFA intakes from fish are associated with lower risk of colorectal cancer among those with genetic variants that result in higher levels of pro-inflammatory mediators. In population-based case-control studies of colon (case $n=1,574)$ and rectal cancer (case $n=791$ ) and diseasefree controls $(n=2,969)$, we investigated interactions between dietary fatty acid intake and 107 candidate polymorphisms and tagSNPs in PTGS1, PTGS2, ALOX12, ALOX5, ALOX15, and FLAP. The two studies used an identical genotyping protocol. We observed interactions and statistically significant increases in colon cancer risk
\end{abstract}

Electronic supplementary material The online version of this article (doi:10.1007/s12263-012-0302-x) contains supplementary material, which is available to authorized users.

N. Habermann $(\square) \cdot$ C. M. Ulrich

National Center for Tumor Diseases, Im Neuenheimer Feld 460, 69120 Heidelberg, Germany

e-mail: nina.habermann@nct-heidelberg.de

N. Habermann · C. M. Ulrich

German Cancer Research Center, Im Neuenheimer Feld 280,

69120 Heidelberg, Germany

A. Lundgreen - M. L. Slattery

Department of Medicine, School of Medicine,

University of Utah, Salt Lake City, UT 84108, USA

K. W. Makar · J. Whitton · R. Galbraith · J. D. Potter Fred Hutchinson Cancer Research Center, Seattle, WA 98109-1024, USA for low docosahexaenoic acid intake among those with the PTGS1 rs10306110 (-1,053 A > G) variant genotypes $(\mathrm{OR}=1.6,95 \%$ confidence interval $=1.1-2.3$, adj. $p=0.06)$ and rectal cancer risk for low total fat intake among those with the variant PTGS1 rs10306122 (7,135 $\mathrm{A}>\mathrm{G})\left(\mathrm{OR}_{\mathrm{vs} . \mathrm{wt}}=1.80,1.02-2.99\right.$; adj. $\left.p=0.08\right)$. The ALOX15 rs11568131 $(10,339 \mathrm{C}>\mathrm{T})$ wild type in combination with a high inflammation score (low EPA intake, high AA intake, no regular NSAID use, high BMI, smoking) was associated with increased colon cancer risk $(\mathrm{OR}=2.28,1.7-3.07)$. Rectal cancer risk was inversely associated with a low inflammation score among PTGS2 rs4648276 (3,934 $\mathrm{T}>\mathrm{C}) \quad$ variant allele carriers $(\mathrm{OR}=0.49,0.25-0.75)$. Overall, these data provide some modest evidence for interactions between dietary fat intake and genetic variation in genes involved in eicosanoid metabolism and colorectal cancer risk.

Keywords Colon cancer - Rectal cancer .

Genetic variants · Fatty acid intake

E. M. Poole

Channing Laboratory, Department of Medicine, Brigham and

Women's Hospital, Harvard Medical School, Boston, MA, USA

E. M. Poole

Department of Epidemiology, Harvard School of Public Health, Boston, MA, USA

B. Caan

Kaiser Permanente Medical Research Program,

Department of Research, Oakland, CA 94611, USA

R. Kulmacz

University of Texas Health Science Center at Houston,

Houston, TX 77030, USA 


\section{Introduction}

Colorectal cancer is one of the most common types of cancer worldwide. Dietary habits contribute substantially to the prevention and causation of colorectal cancer (WCRF, AICR 2007). Specific types of fatty acids (FA) might exert protective effects against certain diseases associated with the Western lifestyle; specifically, recent studies have noted that high serum (Pot et al. 2008) or tissue level (Busstra et al. 2003) of n-3 polyunsaturated fatty acids (PUFA) similar to a high intake of fish containing n-3 PUFA are inversely associated with risk for colorectal cancer (Hall et al. 2008; Norat et al. 2005), and a meta-analysis (Geelen et al. 2007) argues that there is sufficient epidemiologic evidence to suggest that n-3 PUFA may be protective. In contrast, saturated fatty acids (SFA) and n-6 PUFAs may enhance colorectal carcinogenesis (Dommels et al. 2002; Reddy and Maeura 1984; Woutersen et al. 1999).

One putative mechanism through which dietary PUFAs may alter colonic carcinogenesis is the formation of specific eicosanoids, namely prostaglandins, prostacyclins, thromboxanes, leukotrienes, resolvins, and lipoxins. Two enzymatic pathways contribute to the synthesis of many eicosanoids: the prostaglandin-endoperoxide synthase (PTGS; also called cyclooxygenase $(\mathrm{COX})$ ) pathway and the lipoxygenase (ALOX) pathway (which also includes the 5-lipoxygenase-activating protein (FLAP)). Arachidonic acid (AA, 20:4, n-6) is an abundant FA in membrane lipids and can be derived in humans from other dietary n-6 FAs, such as linoleic acid (LA; 18:2, n-6). Many eicosanoids derived from AA have pro-inflammatory properties. Eicosapentaenoic acid (EPA; 20:5, n-3) can also act as a substrate for ALOX and PTGS, resulting in a production of eicosanoids with a slightly different structure but markedly different effects from those arising from AA (Calder 2008). Additionally, EPA can act as a PTGS2 substrate for the generation of E-series resolvins, which appear to exert antiinflammatory actions (Serhan et al. 2008). Generally, EPAderived eicosanoids are much less potent inducers of inflammation than AA-derived eicosanoids (Shapiro et al. 1993). A preponderance of n-6 FAs in the FA supply leads to more prostaglandins of the 2-series and results in a proinflammatory environment. As the proportion of n-3 PUFA relative to n-6 PUFA increases, the proportion of the less inflammatory prostaglandins of the 3-series rises in turn (Lee et al. 1985). Docosahexaenoic acid (DHA; 22:6, n-3) was also described as a substrate for PTGS2 yielding D-series resolvins and docosatrienes, with apparent antiinflammatory properties and cellular protective actions (Serhan 2005). Mediators during the resolution phase of inflammation also involve lipoxins, which are generated by lipoxygenases, preferentially from EPA (Janakiram et al.
2011). Consequently, the dietary FA composition plausibly modulates prostanoid synthesis and the balance between pro- and anti-inflammatory lipid mediators. Major sources of EPA and DHA are fatty fish, such as salmon, tuna, and herring; $\alpha$-linolenic acid (ALA; 18:3, n-3) is found in seeds and seed oils such as flaxseed and canola oils, but conversion of ALA to EPA and DHA is very inefficient in humans (Brenna et al. 2009). Essential FA, including LA, and $\gamma$-linolenic acid (GLA; 18:3, n-6) are more widely found in grains, meats, vegetable oils, and eggs.

Besides inhibiting the synthesis of AA-derived eicosanoids, dietary n-3 PUFAs may inhibit promotion or progression of carcinogenesis by other molecular pathways (Larsson et al. 2004). The regulation of gene transcription by fatty acids seems to involve changes in the activity or abundance of transcription factor families, for example, peroxisome-proliferator-activated receptor (PPAR), liver X receptor (LXR), hepatic nuclear factor $4 \alpha(\mathrm{HNF}-4 \alpha)$, and sterol regulatory element-binding protein (SREBP) (Jump 2002). Findings from previous studies revealed that SNPs in $\operatorname{PPAR} \delta$ can modify the inverse association of NSAID use with colorectal adenomas (Siezen et al. 2006b). These transcription factors play a major role in hepatic carbohydrate, fatty acid, triglyceride, cholesterol, and bile acid metabolism. In the liver, the principal action of n-3 PUFAs involves a shift from lipid synthesis and storage to lipid oxidation (Wang et al. 2010). These effects may contribute to the regulation of whole body lipid metabolism and the control of blood triglycerides and cholesterol, important risk factors for chronic diseases. Other molecular pathways involve an alteration of estrogen metabolism, leading to reduced estrogen-stimulated cell growth, insulin sensitivity and membrane fluidity, and an impairment of the production of free radicals (Larsson et al. 2004).

The associations between FA intakes and colon and rectal cancer have been reported previously in the study populations included in this paper (Slattery et al. 1997a, c, 2001). Intake of n-6 and n-3 FAs were not associated with colon cancer (Slattery et al. 2001). However, Koh et al. (Koh et al. 2004) reported an interaction between dietary intakes of n-6 FAs and the PTGS2 -765 G $>\mathrm{C}$ variant within the Singapore Chinese Health Study, showing an increased risk of colon cancer among those with the GC or CC genotype who consumed a diet high in n-6 FAs. An anti-inflammatory pattern of intake $(>2$ servings fish per week, regular nonsteroidal anti-inflammatory drug (NSAID) use) was shown in a US population to influence associations between colorectal adenoma risk and genetic variability in PTGS1 (Poole et al. 2007).

A large body of evidence suggests that aspirin and other NSAIDs may reduce the risk of colorectal cancer and improve colorectal cancer survival if taken prior to diagnosis (Ulrich et al. 2006). Because NSAIDs inhibit the 
formation of 2-series prostaglandins and 4-series leukotrienes and are thus associated with reduced inflammation, we expected an additional preventive potential of n-3 PUFA intake among NSAID users. However, the influence of single nucleotide polymorphisms (SNPs) in enzymes involved in inflammation-related pathways on associations with the intake of specific FAs and NSAIDs and the risk of colon and rectal cancer is unclear. In the present study, therefore, we have evaluated potential effect modification between 107 tagSNPs and candidate polymorphisms including variable number tandem repeats (VNTR) in PTGS1, PTGS2, ALOX5, ALOX12, ALOX15, and FLAP, NSAID use, and fat and FA intake in relation to risk of colon and rectal cancer.

\section{Methods}

\section{Study population}

The analyses are based on two US population-based casecontrol studies of colon (Slattery et al. 1997b) and rectal cancer (Slattery et al. 1997a) using participants with available DNA. Methods have been described in detail elsewhere; a brief description is provided here.

Colon cancer cases $(n=1,574)$ and controls $(n=1,970)$ and rectal cancer cases $(n=791)$ and controls ( $n=999)$ were recruited from Utah, the Northern California Kaiser Permanente Medical Care Program (KPMCP), and the Twin Cities Metropolitan area of Minnesota (colon cancer study only). Colon cancer cases were diagnosed between October 1, 1991, and September 30, 1994. Rectal cancer cases-including cancer of the rectosigmoid junction or rectum-were diagnosed between May 1997 and May 2001. Participation among contacted colon cancer cases was $76 \%$ (69\% among controls); participation among contacted rectal cancer cases was $73 \%(69 \%$ among controls). Eligible cases were between 30 and 79 years old at the time of diagnosis, English speaking, mentally competent to complete the interview, had no previous history of CRC, and no known (as indicated on the pathology report) familial adenomatous polyposis, ulcerative colitis, or Crohn's disease.

Controls were frequency matched to cases by sex, race, and by 5-year age groups. At KPMCP, controls were randomly selected from membership lists; in Utah, controls 65 years and older were randomly selected from the Health Care Financing Administration lists and controls younger than 65 years were randomly selected from driver's license lists. In Minnesota, controls were selected from driver's license and state-identification lists.

Information on use of aspirin or other NSAIDs, diet, physical activity, weight during the referent year, demographics, and medical history was obtained through questionnaire. Height was measured at the time of interview. Participants reported the average weekly consumption of aspirin and other NSAIDs. Study participants were provided with a list of 14 common aspirin brands and 24 common non-aspirin NSAIDs. Information about regular weekly fish intake for the calendar year 2 years before diagnosis for cases or selection for controls was obtained using a diet history questionnaire.

Dietary-intake data were ascertained using an adaptation of the CARDIA diet history questionnaire which was validated (Slattery et al. 1994a, b), and the assessment method used for this study was described in detail previously (Slattery et al. 1997c). Nutrient values for specific foods were calculated using the Nutrition Coordinating Center (NCC) nutrient database version 19 (Slattery et al. 1994b).

\section{Genotyping}

Genomic DNA was extracted from peripheral white blood cells using the Gentra Puregene kit (Qiagen, Valencia, CA, USA). The SNPs were genotyped using the Illumina GoldenGate bead-based genotyping technology at the Translational Genomics Institute (TGen). Intraplate and interplate replicates at a proportion of $\sim 5 \%$ were included on all plates and in all batches. Blinded duplicates were also included on all plates as another quality control measure. Genotype data from $30 \mathrm{CEPH}$ trios (Coriell Cell Repository, Camden, NJ, USA), genotyped by the HapMap project, were used to confirm the reliability and reproducibility of the genotyping. Genotypes were excluded from analyses if SNPs had $<85 \%$ call rate, $<85 \%$ concordance with blinded or non-blinded duplicates, or Hardy-Weinberg equilibrium (HWE) $p<0.0001$ (see Table S1 for a list of selected polymorphisms). Additionally, candidate PTGS1 SNPs rs5789 (L237M) and rs1236913 (R8W) were confirmed by Taqman in the colon cancer study. Moreover, PTGS1 rs3842787 (P17L) was genotyped by sequencing; sequencing also was used to confirm the genotypes for rs1236913. The ALOX5 and FLAP (=ALOX5AP) VNTRs were genotyped using GeneScan on an ABI 3130xl based on previously published protocols (Poole et al. 2006; Sayers et al. 2003). Briefly, multiplex PCR reactions consisted of $40 \mathrm{ng}$ genomic template DNA, $1.5 \mathrm{mmol} / \mathrm{L} \mathrm{MgCl}_{2}, 1 \times$ PCR Gold Buffer (Applied Biosystems), 0.5 units of Amplitaq Gold Polymerase (Applied Biosystems), $200 \mathrm{nmol} / \mathrm{L}$ each of oligonucleotide primers ALOX5sp1-F: 5'-6FAM-AGGAACAG ACACCTCGCTGAGGAGAG-3', ALOX5sp1-R: 5'-GAG CAGCGAGCGCCGGGAGCCTCGGC-3', ALOX5AP-F: 5'-VIC-CGTG CTCCTCTGCCAAGCCCTGCTTC-3', and ALOX5AP-R02: 5'-GCTCTGCCTCCAGCTG CACAAC CTG-3', $150 \mu \mathrm{mol} / \mathrm{L}$ each of dATP, dCTP, and dTTP, 
$75 \mu \mathrm{mol} / \mathrm{L}$ each of dGTP and 7-deaza-2V-dGTP (Roche Diagnostics GmbH, Mannheim, Germany), and $8 \%$ (v/v) DMSO (Sigma, St. Louis, MO, USA) in $5 \mu \mathrm{L}$. Cycling was at $96{ }^{\circ} \mathrm{C}$ for $7 \mathrm{~min}$, followed by 30 cycles of $94^{\circ} \mathrm{C}$ for $30 \mathrm{~s}, 58{ }^{\circ} \mathrm{C}$ for $30 \mathrm{~s}, 72{ }^{\circ} \mathrm{C}$ for $30 \mathrm{~s}$, and finally $72{ }^{\circ} \mathrm{C}$ for 7 min. The observed 6-FAM-labeled ALOX5 amplicon lengths ranged from $254 \mathrm{bp}$ (26 bp repeats) to $290 \mathrm{bp}$ (86 bp repeats), and VIC-labeled FLAP amplicon was either 212 bp (19A) or 216 bp (23A).

\section{Statistical methods}

Unless otherwise indicated, all statistical analyses were performed using $\mathrm{SAS}^{\circledR}$ version 9.2 (SAS Institute, Cary, NC, USA). The minor allele frequency (MAF), test for HWE, and measure of linkage disequilibrium (LD) were calculated among Caucasian controls using the SAS ALLELE procedure. We report odds ratios (ORs) and $95 \%$ confidence intervals (95\% CIs) assessed from multiple logistic regression models for colon and rectal cancer separately. In addition to the minimal adjustments for age, study center, race/ethnicity, and sex, the logistic regression models were also adjusted for family history of disease, recent NSAID use (where appropriate), BMI, physical activity, dietary cholesterol, and caloric intake. Risk estimates were assessed based on the additive inheritance model, unless the dominant model appeared to be more appropriate [i.e., MAF $<0.1$ or similar risk among heterozygote (het) and homozygote variant (hzv)] for which the dominant model was used.

We evaluated possible interactions between tagSNPs and intakes of total fat and specific FA according to following FA groups: SFA (=4:0, 6:0, 8:0, 10:0, 12:0, 14:0, 16:0, 17:0, 18:0, 20:0, 22:0), monounsaturated fatty acids $($ MUFA $=14: 1,16: 1,18: 1,20: 1,22: 1)$, PUFA $(=18: 2$, 18:3, 20:4, 20:5, 22:6), n-3 PUFA (=18:3, 20:5, 22:6), as well as specific FA: LA, AA, EPA, and DHA because of the mechanisms hypothesized for these genes. Initially, continuous FA levels were categorized into tertiles based on sex, but to increase power when stratifying by NSAID use, the FA levels were dichotomized, at the median, into low- and high-intake groups.

$p$ values for interaction were determined using a onedegree-of-freedom likelihood ratio test. The Bonferroni correction was used to adjust interaction $p$ values for multiple comparisons at the gene level, and, as this is a very conservative test, both unadjusted and adjusted $p$ values are given.

To summarize risk associated with relevant exposures, an inflammation summary score was created that consisted of low- and high-inflammatory diet and lifestyle factors. In creating the score, participants were assigned values ranging from zero (low risk) to two (high risk) based on exposure levels. For dichotomous variables such as NSAID use and smoking, a zero was assigned for those at low risk (current or recent NSAID users; never or non-recent smoker) and a two for high risk (never or non-recent NSAID users; current or recent smokers). For BMI, total fat, AA, and EPA intake, participants at low risk were assigned a zero (BMI $<25 \mathrm{~kg} / \mathrm{m}^{2}$; lowest tertiles for total fat and arachidonic acid; highest tertile for eicosapentaenoic acid intake), a one for intermediate levels of risk $\left(25 \mathrm{~kg} / \mathrm{m}^{2} \leq \mathrm{BMI} \leq 30 \mathrm{~kg} / \mathrm{m}^{2}\right.$; intermediate dietary levels), and a two for high risk (BMI $>30 \mathrm{~kg} / \mathrm{m}^{2}$; highest tertiles for total fat and AA; lowest tertile for EPA). After assigning a score for each exposure, the scores were summed to generate an individual inflammation summary score. The continuous score variable was then redefined as approximate quartiles.

\section{Results}

\section{Study population}

Characteristics of the genotyped participants are presented in Table 1. Briefly, the study population was mostly Caucasian (colon study $>90 \%$; rectum study $>80 \%$ ). Current aspirin or NSAID use was more frequently reported by controls than cases. Cases more commonly reported having a family history of colorectal cancer, a higher total energy intake, less physical activity, and higher intake of dietary cholesterol than controls. Cases also had a statistically significantly higher intake of total fat, SFA, MUFA, PUFA (colon cases only), LA (colon cases only), and n-3 PUFA, though the associations were stronger for colon cancer than for rectal cancer.

\section{SNP association: interaction with fat and FA intake}

We observed several interactions between fat and FA intake and SNPs in PTGS1 and ALOX15 for colon cancer (Table 2) and SNPs in PTGS1 and ALOX12 for rectal cancer risk (Table 3). We observed a possible increase in colon cancer risk among those with low intakes of the marine n-3 PUFAs EPA and DHA and the PTGS1 rs10306110 $(-1,053 \mathrm{~A}>\mathrm{G})$ variant genotype (EPA: $\mathrm{OR}_{\text {vs.wt }}=1.56, \quad 95 \% \quad \mathrm{CI}=1.09-2.22, \quad p$-interaction $=0.006$, adj. $p=0.1 ;$ DHA: $\mathrm{OR}_{\mathrm{vs} . \mathrm{wt}}=1.62,95 \%$ $\mathrm{CI}=1.14-2.30$, and $p$-interaction $=0.003$, adj. $p=0.06$ ). The interaction of PTGS1 rs10306110 and DHA intake remained marginally significant after Bonferroni correction. Carriers of the ALOX15 rs11568131 (10,339 $\mathrm{C}>\mathrm{T}$ ) wild-type alleles who had high intake of EPA $\left(\mathrm{OR}_{\mathrm{vs} . \text { low intake }}=0.80,95 \% \mathrm{CI}=0.65-0.98, p\right.$-interaction $=0.02$, adj. $p=0.36$ ) were at lower risk than those 
Table 1 Demographic characteristics and descriptive statistics of genotyped study participants

\begin{tabular}{|c|c|c|c|c|c|c|}
\hline & \multicolumn{2}{|l|}{ Colon } & \multirow[t]{2}{*}{$p$} & \multicolumn{2}{|l|}{ Rectum } & \multirow[t]{2}{*}{$p$} \\
\hline & $\begin{array}{l}\text { Control } \\
n=1,900 \\
n(\%)\end{array}$ & $\begin{array}{l}\text { Case } \\
n=1,543 \\
n(\%)\end{array}$ & & $\begin{array}{l}\text { Control } \\
n=912 \\
n(\%)\end{array}$ & $\begin{array}{l}\text { Case } \\
n=712 \\
n(\%)\end{array}$ & \\
\hline \multicolumn{7}{|l|}{ Age } \\
\hline $30-39$ & $40(2.1)$ & $23(1.5)$ & & $17(1.9)$ & $19(2.7)$ & \\
\hline $40-49$ & $127(6.7)$ & $100(6.5)$ & & $100(11.0)$ & 85 (11.9) & \\
\hline $50-59$ & $315(16.6)$ & 289 (18.7) & & $230(25.2)$ & $188(26.4)$ & \\
\hline $60-69$ & $651(34.2)$ & $535(34.7)$ & & $316(34.7)$ & $236(33.2)$ & \\
\hline $70-79$ & $767(40.4)$ & 596 (38.6) & & $249(27.3)$ & $184(25.8)$ & \\
\hline Mean & 65.0 & 64.88 & NA & 62.2 & 61.46 & NA \\
\hline \multicolumn{7}{|l|}{ Center } \\
\hline Utah & $347(18.3)$ & $250(16.2)$ & NA & $343(37.6)$ & $248(34.8)$ & NA \\
\hline KPMCP & $760(40.0)$ & $720(46.7)$ & & $569(62.4)$ & $464(65.2)$ & \\
\hline Minnesota & $793(41.7)$ & $573(37.1)$ & & NA & NA & \\
\hline \multicolumn{7}{|l|}{ Race/ethnicity } \\
\hline NHW & 1,773 (93.3) & 1,417 (91.8) & NA & $782(85.8)$ & $589(82.7)$ & NA \\
\hline Hispanic & $72(3.8)$ & $56(3.6)$ & & $63(6.9)$ & $57(8.0)$ & \\
\hline Black & 55 (2.9) & $70(4.5)$ & & $40(4.3)$ & $28(3.9)$ & \\
\hline Asian & NA & NA & & $27(3.0)$ & $38(5.3)$ & \\
\hline \multicolumn{7}{|l|}{ Sex } \\
\hline Male & $1,010(53.2)$ & $862(55.9)$ & NA & $512(56.1)$ & $427(60.0)$ & NA \\
\hline Female & $890(46.8)$ & $681(44.1)$ & & $400(43.9)$ & $285(40.0)$ & \\
\hline \multicolumn{7}{|l|}{ Aspirin/NSAID use } \\
\hline No recent use & $1,099(58.3)$ & $1,042(68.3)$ & $<0.0001$ & $497(55.0)$ & $449(63.0)$ & 0.0005 \\
\hline Recent use & $787(41.7)$ & $485(31.8)$ & & $407(45.0)$ & $257(36.4)$ & \\
\hline \multicolumn{7}{|c|}{ Family history of CRC, $n(\%)$} \\
\hline Yes & $180(9.5)$ & $251(16.3)$ & $<0.0001$ & $76(8.3)$ & $83(11.7)$ & 0.03 \\
\hline No & $1,720(90.5)$ & $1,292(83.7)$ & & $836(91.7)$ & $629(88.3)$ & \\
\hline Total energy intake (kcal) & 2,320 & 2,451 & 0.0005 & 2,595 & 2,752 & 0.02 \\
\hline \multicolumn{7}{|l|}{ Long term PAI } \\
\hline Mean & 7.0 & 6.5 & $<0.0001$ & 7.6 & 7.0 & 0.0004 \\
\hline \multicolumn{7}{|l|}{ BMI } \\
\hline- & 26.7 & 27.8 & $<0.0001$ & 27.4 & 27.7 & 0.18 \\
\hline Fat/fatty acid intake & $(\mathrm{g})$ & $(\mathrm{g})$ & & (g) & $(\mathrm{g})$ & \\
\hline Total fat & 84.1 & 91.5 & $<0.0001$ & 103.2 & 111.2 & 0.02 \\
\hline SFA & 31.3 & 34.0 & 0.0002 & 34.8 & 37.6 & 0.02 \\
\hline MUFA & 30.3 & 33.1 & $<0.0001$ & 37.0 & 40.1 & 0.01 \\
\hline PUFA & 15.8 & 17.0 & 0.0001 & 23.7 & 25.1 & 0.07 \\
\hline LA & 13.9 & 15.0 & 0.0001 & 21.1 & 22.4 & 0.09 \\
\hline AA & 0.14 & 0.2 & $<0.0001$ & 0.12 & 0.14 & 0.0002 \\
\hline EPA & 0.02 & 0.02 & 0.60 & 0.02 & 0.02 & 0.22 \\
\hline DHA & 0.08 & 0.08 & 0.25 & 0.08 & 0.09 & 0.07 \\
\hline n-3 PUFA & 1.8 & 1.9 & 0.0003 & 2.4 & 2.6 & 0.01 \\
\hline Dietary cholesterol (mg) & 275 & 308 & $<0.0001$ & 305 & 351 & $<0.0001$ \\
\hline
\end{tabular}

$B M I$ body mass index (weight/height ${ }^{2}$ for men, weight/height ${ }^{1.5}$ for women), PAI physical activity index, $S F A$ saturated fatty acids $=4: 0,6: 0$, 8:0, 10:0, 12:0, 14:0, 16:0, 17:0, 18:0, 20:0, 22:0, MUFA monounsaturated fatty acids = 14:1, 16:1, 18:1, 20:1, 22:1, PUFA polyunsaturated fatty acids $=18: 2,18: 3,20: 4,20: 5,22: 6, n-3$ PUFA $=18: 3,20: 5,22: 6, N H W$ non-Hispanic Whites, NSAIDs nonsteroidal anti-inflammatory drugs, $C R C$ colorectal cancer

Bold values are statistically significant 
Table 2 Associations of SNPs in PTGS1 and ALOX15 and risk of colon cancer stratified by fat and fatty acid intake

\begin{tabular}{|c|c|c|c|c|c|c|}
\hline \multirow[t]{2}{*}{ Gene } & \multirow[t]{2}{*}{ SNP } & \multirow[t]{2}{*}{ Fat/fatty acid } & \multirow[t]{2}{*}{ Genotype } & \multicolumn{3}{|c|}{ Colon fat/fatty acid intake } \\
\hline & & & & $\begin{array}{l}\text { Low } \\
\text { OR }^{\text {a }}(95 \% \mathrm{CI})\end{array}$ & $\begin{array}{l}\text { Intermediate } \\
\mathrm{OR}^{\mathrm{a}}(95 \% \mathrm{CI})\end{array}$ & $\begin{array}{l}\text { High } \\
\mathrm{OR}^{\mathrm{a}}(95 \% \mathrm{CI})\end{array}$ \\
\hline \multirow[t]{8}{*}{ PTGS1 } & rs 10306110 & EPA & AA & 1.00 & $1.05(0.87,1.27)$ & $0.99(0.82,1.19)$ \\
\hline & $(-1,053 \mathrm{~A}>\mathrm{G})$ & & AG/GG & $1.56(1.09,2.22)$ & $1.10(0.77,1.57)$ & $0.77(0.54,1.10)$ \\
\hline & & & $p$-interaction ${ }^{\mathrm{a}}$ & & 0.006 & \\
\hline & & & Adjusted $p^{\mathrm{b}}$ & & 0.10 & \\
\hline & & DHA & AA & 1.00 & $1.16(0.96,1.40)$ & $1.07(0.88,1.31)$ \\
\hline & & & AG/GG & $1.62(1.14,2.30)$ & $1.17(0.82,1.66)$ & $0.82(0.57,1.18)$ \\
\hline & & & $p$-interaction ${ }^{\mathrm{a}}$ & & 0.003 & \\
\hline & & & Adjusted $p^{\mathrm{b}}$ & & 0.06 & \\
\hline \multirow[t]{4}{*}{ ALOX15 } & rs11568131 & EPA & GG & 1.00 & $0.98(0.80,1.20)$ & $0.80(0.65,0.98)$ \\
\hline & $(10,339 \mathrm{C}>\mathrm{T})$ & & GA/AA & $0.80(0.60,1.05)$ & $0.86(0.66,1.14)$ & $1.00(0.76,1.32)$ \\
\hline & & & $p$-interaction ${ }^{\mathrm{a}}$ & & 0.02 & \\
\hline & & & Adjusted $p^{\mathrm{b}}$ & & 0.36 & \\
\hline
\end{tabular}

Only SNPs with statistically significant interactions are shown

Bold values are statistically significant

a Adjusted for age, study center, ethnicity, sex, family history of disease, recent NSAID use (where appropriate), BMI, physical activity, dietary cholesterol, and caloric intake

b Bonferroni adjusted

Table 3 Associations of SNPs in PTGS1 and ALOX12 2 and risk of rectal cancer stratified by fat and fatty acid intake

\begin{tabular}{|c|c|c|c|c|c|c|}
\hline \multirow[t]{2}{*}{ Gene } & \multirow[t]{2}{*}{ SNP } & \multirow[t]{2}{*}{ Fat/fatty acid } & \multirow[t]{2}{*}{ Genotype } & \multicolumn{3}{|c|}{ Rectum fat/fatty acid intake } \\
\hline & & & & $\begin{array}{l}\text { Low } \\
\text { OR }^{\mathrm{a}}(95 \% \mathrm{CI})\end{array}$ & $\begin{array}{l}\text { Intermediate } \\
\mathrm{OR}^{\mathrm{a}}(95 \% \mathrm{CI})\end{array}$ & $\begin{array}{l}\text { High } \\
\mathrm{OR}^{\mathrm{a}}(95 \% \mathrm{CI})\end{array}$ \\
\hline \multirow[t]{8}{*}{ PTGS1 } & rs10306122 (2,125 T > C) & Total fat & AA & 1.00 & $0.94(0.69,1.27)$ & $1.12(0.77,1.62)$ \\
\hline & & & AG/GG & $1.75(1.02,2.99)$ & $1.22(0.70,2.11)$ & $0.76(0.46,1.28)$ \\
\hline & & & $p$-interaction ${ }^{\mathrm{a}}$ & & 0.005 & \\
\hline & & & Adjusted $p^{\mathrm{b}}$ & & 0.08 & \\
\hline & & MUFA & AA & 1.00 & $0.97(0.71,1.32)$ & $1.15(0.80,1.67)$ \\
\hline & & & AG/GG & $1.84(1.07,3.18)$ & $1.03(0.60,1.77)$ & $0.87(0.51,1.46)$ \\
\hline & & & $p$-interaction ${ }^{\mathrm{a}}$ & & 0.01 & \\
\hline & & & Adjusted $p^{\mathrm{b}}$ & & 0.16 & \\
\hline \multirow[t]{12}{*}{ ALOX12 } & $\operatorname{rs} 11571339(7,135 \mathrm{~A}>\mathrm{G})$ & $n-3$ & AA & 1.00 & $1.14(0.83,1.57)$ & $0.91(0.64,1.31)$ \\
\hline & & & AG/GG & $0.47(0.23,0.93)$ & $1.29(0.77,2.19)$ & $1.05(0.63,1.73)$ \\
\hline & & & $p$-interaction ${ }^{\mathrm{a}}$ & & 0.046 & \\
\hline & & & Adjusted $p^{\mathrm{b}}$ & & 0.79 & \\
\hline & & 18:02 & AA & 1.00 & $0.92(0.66,1.28)$ & $0.89(0.63,1.27)$ \\
\hline & & & AG/GG & $0.45(0.21,0.95)$ & $0.90(0.53,1.55)$ & $1.07(0.66,1.73)$ \\
\hline & & & $p$-interaction ${ }^{\mathrm{a}}$ & & $\mathbf{0 . 0 3}$ & \\
\hline & & & Adjusted $p^{\mathrm{b}}$ & & 0.50 & \\
\hline & & PUFA & AA & 1.00 & $0.95(0.69,1.32)$ & $0.87(0.61,1.23)$ \\
\hline & & & AG/GG & $0.48(0.23,1.00)$ & $0.87(0.50,1.49)$ & $1.08(0.67,1.75)$ \\
\hline & & & $p$-interaction ${ }^{\mathrm{a}}$ & & 0.02 & \\
\hline & & & Adjusted $p^{\mathrm{b}}$ & & 0.41 & \\
\hline
\end{tabular}

Only SNPs with statistically significant interactions are shown

Bold values are statistically significant

a Adjusted for age, study center, ethnicity, sex, family history of disease, recent NSAID use (where appropriate), BMI, physical activity, dietary cholesterol, and caloric intake

${ }^{\mathrm{b}}$ Bonferroni adjusted 
with low EPA intake; after adjusting for multiple comparisons, however, this interaction was not statistically significant. The variant PTGS1 rs10306122 (7,135 A > G) allele together with a low intake of total fat $\left(\mathrm{OR}_{\mathrm{vs} . \mathrm{wt}}=1.80,95 \%\right.$ $\mathrm{CI}=1.02-2.99 ; p$-interaction $=0.005$, adj. $p=0.08)$ or MUFA $\left(\mathrm{OR}_{\mathrm{vs} . \mathrm{wt}}=1.84,95 \% \mathrm{CI}=1.07-3.18 ; p\right.$-interaction $=0.01$, adj. $p=0.16)$ was associated with an increased risk of rectal cancer. The ALOX12 rs11571339 (7,135 $A>G)$ showed statistically significant interactions with three types of FA variables: n-3 PUFA, LA, and PUFA (n-3 PUFA: $p$-interaction $=0.046$, adj. $p=0.79$; LA: $p$-interaction $=0.03$, adj. $p=0.5$; PUFA: $p$-interaction $=0.02$, adj. $p=0.41$ ). In all cases, the variant genotypes (AG/GG vs. AA) were associated with an approximately halving of risk among those with low n-3 PUFA $\left(\mathrm{OR}_{\mathrm{vs} . \mathrm{wt}}=0.47,95 \%\right.$ $\mathrm{CI}=0.23-0.93), \mathrm{LA}\left(\mathrm{OR}_{\mathrm{vs} . \mathrm{wt}}=0.45,95 \% \mathrm{CI}=0.21-\right.$ $0.95)$, or PUFA $\left(\mathrm{OR}_{\mathrm{vs} . \mathrm{wt}}=0.48,95 \% \mathrm{CI}=0.23-1.00\right)$ intake. However, none of these findings for rectal cancer remained statistically significant after adjusting for multiple comparisons.

\section{Inflammation risk score}

Following our hypothesis, we characterized individual inflammation susceptibility as being high for those with low intakes of EPA, a high intake of total fat or AA, no regular NSAID use, a high BMI, and smoking. The ALOX15 rs11568131 (10,339 $\quad \mathrm{C}>\mathrm{T})$ wild type together with a high inflammation score was associated with the highest risk of developing colon cancer $\left(\mathrm{OR}_{\mathrm{vs} . \text { low }}\right.$ score $=2.28,95 \% \mathrm{CI}=1.70-3.07, p$-interaction $=0.04$; Fig. 1a). Low risk for rectal cancer was associated with a low inflammation status among carriers of the variant PTGS2 rs4648276 $(3,934 \mathrm{~T}>\mathrm{C})$ allele $\left(\mathrm{OR}_{\mathrm{vs} . \mathrm{wt}}=0.49, \quad 95 \% \quad \mathrm{CI}=0.25-1.96, \quad p\right.$-interaction $=0.02$; Fig. 1b).

For functional candidate polymorphisms, no statistically significant results or meaningful interactions were observed, see significant results of the tested SNPs and their interaction with NSAID use stratified for fat and FA intake in Tables 4 and 5.

\section{Discussion}

In this study, we used a tagSNP approach to examine the interaction of 107 genetic polymorphisms in six genes within eicosanoid-metabolism pathways, with fat and FA intake on colon and rectal cancer risk. Our candidate genes included PTGS1 and PTGS2, two central enzymes in the biosynthetic pathway of prostaglandins from AA; ALOX5, $A L O X 12$, and $A L O X 15$, which catalyze the conversion of FA hydroperoxides from PUFAs; and FLAP, which is crucial for the activation of $A L O X 5$ and therefore for the production of leukotrienes. We investigated both candidate polymorphisms with defined functional impact and tagSNPs.

FA metabolism by $A L O X$ and PTGS enzymes has been shown to contribute to carcinogenesis in colonic tissue. We investigated whether polymorphisms in the genes encoding these enzymes, in combination with FA intake, alter colon and rectal cancer risk. We observed statistically significant associations between different fatty acid intake patterns and colon cancer risk for polymorphisms in PTGS1 rs10306110 (-1,053 A $>\mathrm{G})$ and $A L O X 15$ rs11568131 $(10,339 \mathrm{C}>\mathrm{T})$ on the one hand and rectal cancer risk for polymorphisms in PTGS1 rs10306122 $(2,125 \mathrm{~T}>\mathrm{C})$ and ALOX12 rs11571339 (7,135 A $>\mathrm{G})$ on the other. These are novel findings; none of the SNPs was previously hypothesized as being associated with a particular FA intake pattern and colon or rectal cancer risk. The rs 10306110 variant is located $5^{\prime}$ to the PTGS1 gene and is in high LD $\left(r^{2}>0.8\right)$ with four SNPs located $5^{\prime}$ to the PTGS1 gene (rs10306114, rs10306109, rs10306108, and rs115693689) and a non-synonymous rs3842787 (L15L16del). The rs3842787 genotype also was assessed within this study but was not associated with fat or FA intake and colon or rectal tumors. It can be hypothesized that the rs11568131 ALOX15 polymorphism at the $3^{\prime}$ UTR may result in functional consequences as polymorphisms in these gene regions may inhibit translation of the enzyme when the miRNA-RNA-induced silencing complex binds to its target. The rs10306122 $(2,125 \mathrm{~T}>\mathrm{C})$ is located in an intronic region of PTGS2 as is the $A L O X 12$ variant rs11571339 $(7,135 \mathrm{~A}>\mathrm{G})$. There is no other SNP in a high LD that can explain the association of the SNP with fat and FA intake and rectal cancer risk modification.

We used an inflammation risk score to evaluate whether the combination of specific lifestyle with genetic factors could influence the risk of developing colon or rectal cancer. This approach has not previously been used to evaluate interactions with these genes and colon and rectal cancer risk. We found that the wild-type ALOX15 rs11568131 (10,339 C > T) was associated with increased risk for persons with a higher inflammation score. Persons with homo- or heterozygous for PTGS2 rs4648276 (3,934 $\mathrm{T}>\mathrm{C})$ and the lowest inflammation scores (0-3) had the lowest risk of developing rectal cancer. The rs4648276 SNP is located in an intron region of the PTGS2 gene and is in high LD with SNPs $5^{\prime}$ and $3^{\prime}$ to the PTGS2 gene (rs20417 and rs689465, as well as rs4648307 and rs4648308, respectively).

Our analysis included a number of candidate SNPs. These are SNPs leading to missense mutations of PTGS1 (rs1236913 (R8W), rs5789 (L237M), rs3842787 (P17L), rs10306140 (R149L), and ALOX12 (rs434473), as well as 


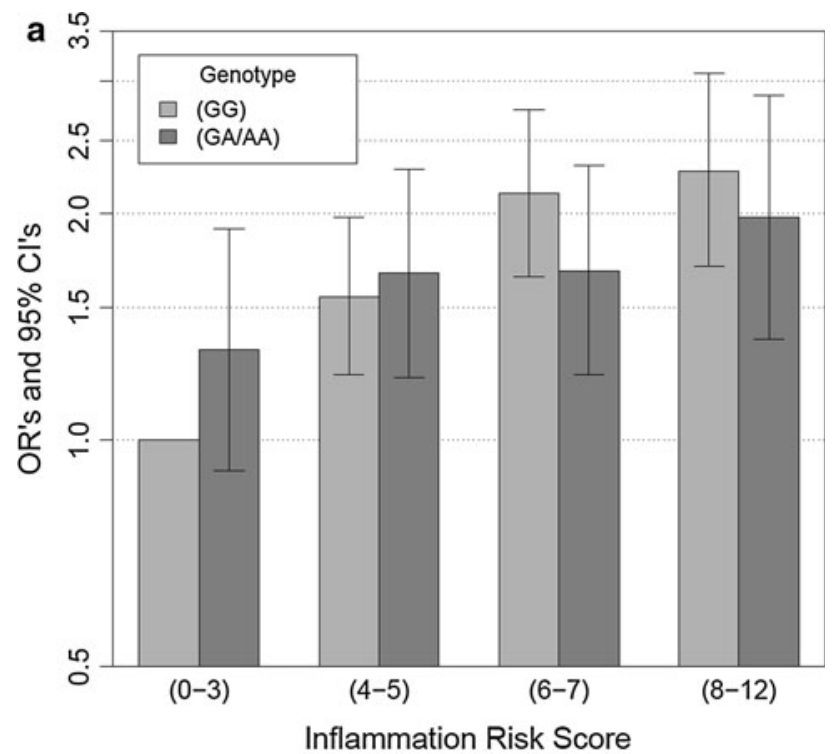

b

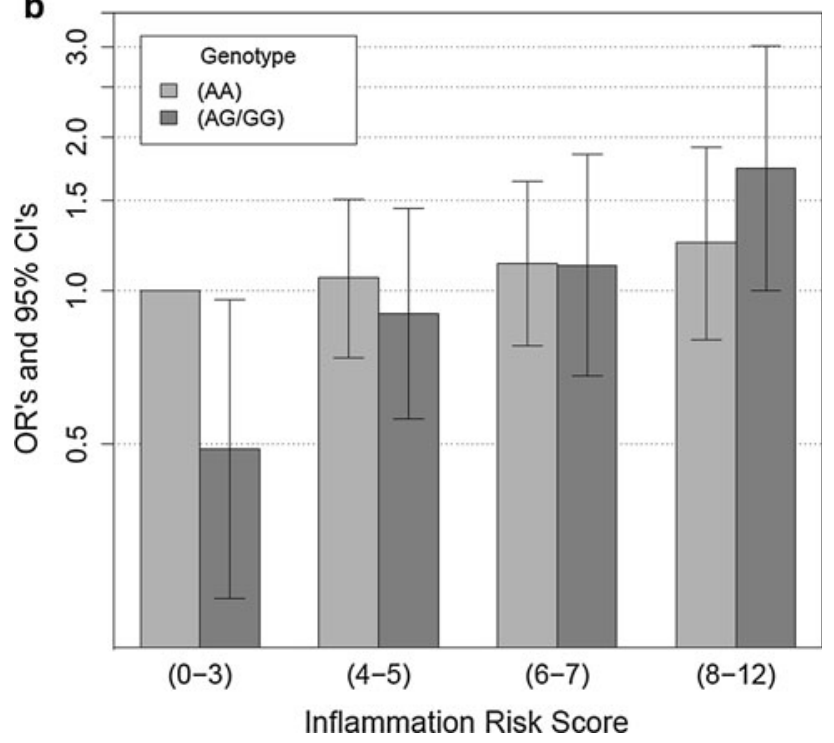

Fig. 1 Inflammation risk score based on NSAID/aspirin use (score of 0 for recent user and score of 2 for non-recent user), smoking (score of 0 for non-recent smoker and 2 for recent smoker), BMI [score of 0 for normal $(<25), 1$ for overweight (25-29), and 2 for obese ( $>29)$ ], total fat intake (score of 0 for lowest tertile, 1 for middle tertile, and 2 for highest tertile), arachidonic acid intake (score of 0 for highest tertile, 1 for middle tertile, and 2 for lowest tertile), and eicosapentaenoic acid intake (similar interactions assessed for SNP (rs20417) or group of SNPs (rs2066826, ra4648276 and 4648308) in high linkage disequilibrium $\left(r^{2}>0.8\right)$ with rs20432), adjusted for age, center, race, sex, and kcal. Shown are the significant results for a colon and b rectal cancer

SNPs in the 5' UTR (PTGS2: rs20417, rs5270; ALOX5: rs4986832 (G-1699A)) and in the $3^{\prime}$ UTR (PTGS2 rs689469). However, none of these variants showed statistically significant interactions with n-3 PUFA (or NSAID use) on CRC risk. Compared with the wild type, the COX1 activity associated with the PTGS1 rs1236913 has been found to be more resistant to inhibition by indomethacin; the rs5789- and rs3842787-variant proteins exhibited lower uninhibited COX-1 activity (Lee et al. 2007). The nonsynonymous mutation in the ALOX12 rs434473 variant results in the substitution of serine for asparagine at position 322. The possible functional effect of this substitution on enzymatic activity remains to be tested. The rs 20417 SNP is located in the PTGS2 promoter and carriers of this variant have decreased gene expression and a lower risk of colorectal adenoma comparable to the use of NSAIDs (Ulrich et al. 2005). The ALOX5 rs4986832 variant is hypothesized to result in enhanced binding of the transcription factor and, due to its location in a negative regulatory region of the promoter, decreased transcription of ALOX5 (Hoshiko et al. 1990; Goodman et al. 2004). However, rs 4986832 has been shown to be associated with a decreased colon cancer risk in Caucasians (Goodman et al. 2004). The impact of two VNTRs was also analyzed in this study. Fewer repeats of the $6 \mathrm{bp}$ VNTR [-176 (GGGCGG)2-8] in the ALOX5 promoter have been associated with lower gene expression (In et al. 1997) and may decrease risk of colorectal polyps, though this association did not reach statistical significance in a previous study (Poole et al. 2006). Within the FLAP promoter, a dichotomous poly(A) repeat polymorphism at position -169 to -146 results in 19A and 23 A alleles; however, no effects on basal transcription of FLAP were reported (Sayers et al. 2003). The present study is the first to test for an interaction between the FLAP VNTR and fat and FA intake on the risk of colon or rectal cancer, for which we found limited support.

There are some potential limitations to this study. The quantification of the FA intake based on a diet history questionnaire may give rise to inaccuracies due to recall difficulties and to incomplete FA content information in nutrient databases (Slattery et al. 1997c). However, our questionnaire is extremely detailed and its nutrient database is one of the most comprehensive ones available for assessing FA. Quantification of the FA composition of plasma lipids would provide more detailed information, but is not practical in a study of this size. Perhaps the greatest limitation is the number of comparisons made, although this is essential, at this stage of our understanding, to evaluate the data and understand the associations that exist. Although we used the Bonferroni correction, a conservative method of adjustment, it is still possible that reported associations could be spurious. Conversely, true associations may have been missed because of the stringency of the multiple-comparison adjustment. Finally, considerations must be given to other genes that could interact with FA intake and NSAID use. Effect modifications for the protective effect of NSAID use against colorectal adenoma were shown, for example, for polymorphisms in PPAR $\delta$ 


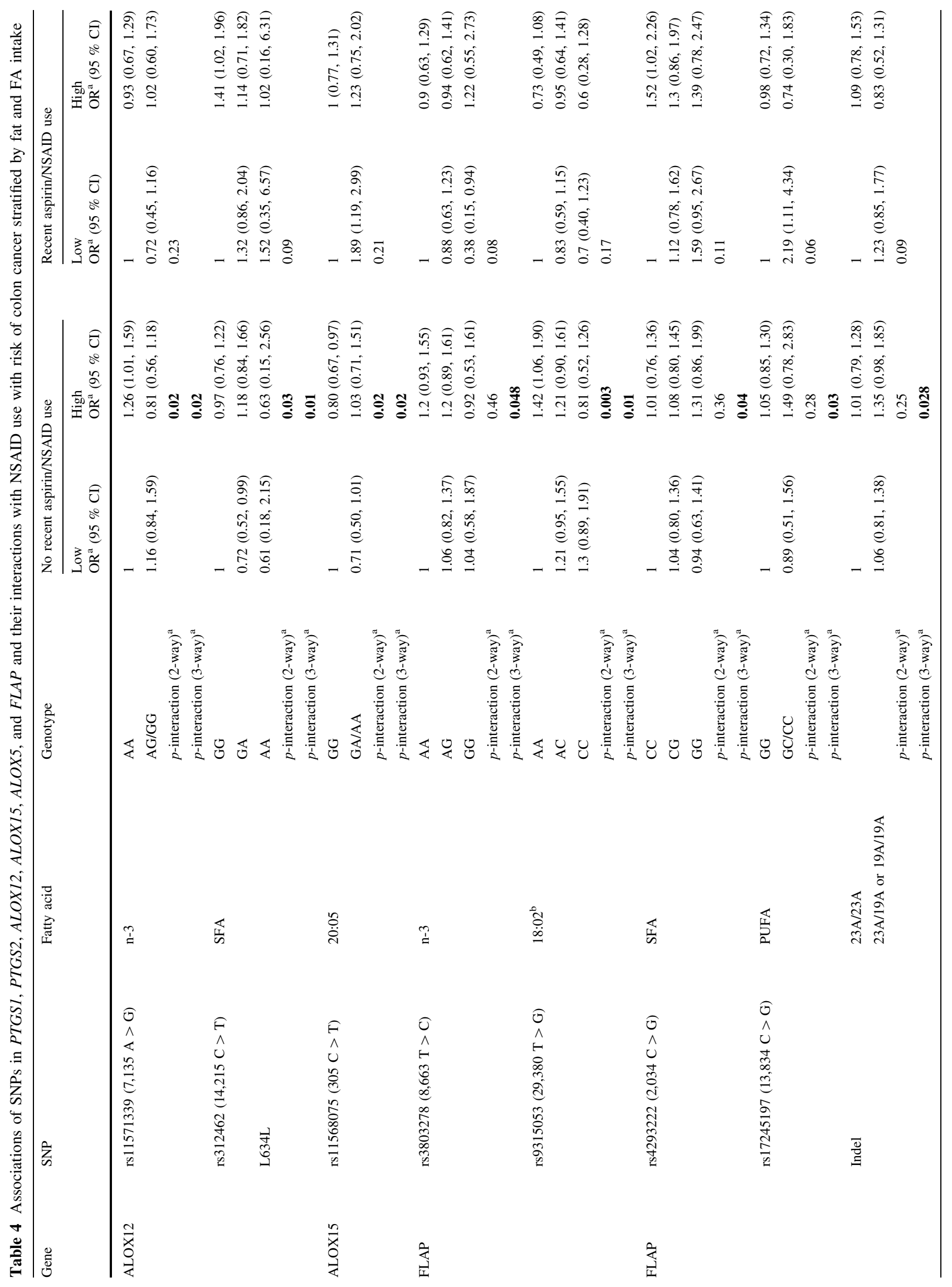




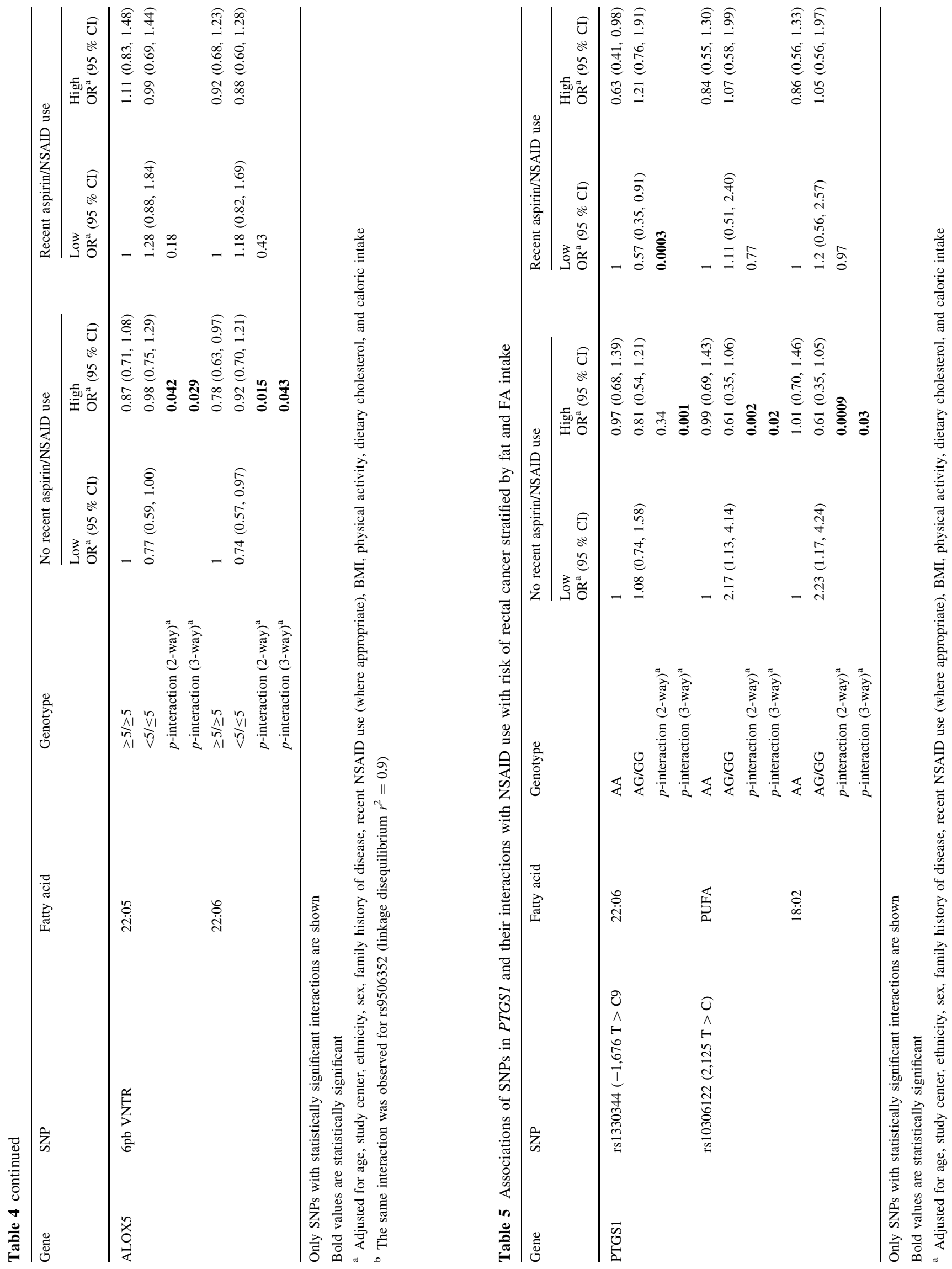


(Siezen et al. 2006b) and for polymorphisms in p53 for colorectal carcinoma (Tan et al. 2007). However, SNPs in genes within these molecular pathways were not included in this study. The impact of specific FA intake as effect modifier is much less described. A high n-3 PUFA intake (inferred from high fish consumption) modified the associations of colorectal adenoma and SNPs in AA-pathway genes, such as COX-2 and PPAR $\delta$ (Siezen et al. 2005, 2006a). Our study appears to be the first to consider a joint interaction of both FA intake and NSAID use.

Our study has several strengths. By investigating tagSNPs, we achieved comprehensive coverage of genetic variability in PTGS1, PTGS2, ALOX5, ALOX12, ALOX15, and FLAP. The inclusion of data on fat and FA intake, as well as on aspirin and other NSAID use, together with the large number of cases and controls, allows the joint exploration of the influence of fat/FA intake and NSAID use on the risk of colon and rectal cancers. Additional observational and functional studies will be needed before the combined effects of fat/FA intake and inflammation on the risk of colorectal cancer are clear.

Acknowledgments The authors would like to thank Lisel Koepl, MPH, Anna Coghill, MPH, Sandie Edwards, MS, and Li Hsu, PhD, for their contributions to the studies. Financial support was granted by the National Institutes of Health (Grants R01 CA 89445 and R01 CA 59045, CA48998).

\section{References}

Brenna JT, Salem N Jr, Sinclair AJ, Cunnane SC (2009) Alphalinolenic acid supplementation and conversion to n-3 long-chain polyunsaturated fatty acids in humans. Prostaglandins Leukot Essent Fatty Acids 80(2-3):85-91. doi:10.1016/j.plefa.2009. 01.004

Busstra MC, Siezen CL, Grubben MJ, van Kranen HJ, Nagengast FM, van't Veer P (2003) Tissue levels of fish fatty acids and risk of colorectal adenomas: a case-control study (Netherlands). Cancer Causes Control 14(3):269-276

Calder PC (2008) The relationship between the fatty acid composition of immune cells and their function. Prostaglandins Leukot Essent Fatty Acids 79(3-5):101-108. doi:10.1016/j.plefa.2008.09.016

Dommels YEM, Alink GM, van Bladeren PJ, van Ommen B (2002) Dietary n-6 and n-3 polyunsaturated fatty acids and colorectal carcinogenesis: results from cultured colon cells, animal models and human studies. Environ Toxicol Pharmacol 11(3-4):297-308

Geelen A, Schouten JM, Kamphuis C, Stam BE, Burema J, Renkema JM, Bakker EJ, van't Veer P, Kampman E (2007) Fish consumption, n-3 fatty acids, and colorectal cancer: a metaanalysis of prospective cohort studies. Am J Epidemiol 166(10): 1116-1125. doi:10.1093/aje/kwm197

Goodman JE, Bowman ED, Chanock SJ, Alberg AJ, Harris CC (2004) Arachidonate lipoxygenase (ALOX) and cyclooxygenase (COX) polymorphisms and colon cancer risk. Carcinogenesis 25(12):2467-2472. doi:10.1093/carcin/bgh260

Hall MN, Chavarro JE, Lee IM, Willett WC, Ma J (2008) A 22-year prospective study of fish, n-3 fatty acid intake, and colorectal cancer risk in men. Cancer Epidemiol Biomarkers Prev 17(5):1136-1143. doi:10.1158/1055-9965.EPI-07-2803

Hoshiko S, Radmark O, Samuelsson B (1990) Characterization of the human 5-lipoxygenase gene promoter. Proc Natl Acad Sci USA 87(23):9073-9077

In KH, Asano K, Beier D, Grobholz J, Finn PW, Silverman EK, Silverman ES, Collins T, Fischer AR, Keith TP, Serino K, Kim SW, De Sanctis GT, Yandava C, Pillari A, Rubin P, Kemp J, Israel E, Busse W, Ledford D, Murray JJ, Segal A, Tinkleman D, Drazen JM (1997) Naturally occurring mutations in the human 5-lipoxygenase gene promoter that modify transcription factor binding and reporter gene transcription. J Clin Investig 99(5):1130-1137

Janakiram NB, Mohammed A, Rao CV (2011) Role of lipoxins, resolvins, and other bioactive lipids in colon and pancreatic cancer. Cancer Metastasis Rev 30(3-4):507-523. doi:10.1007/ s10555-011-9311-2

Jump DB (2002) Dietary polyunsaturated fatty acids and regulation of gene transcription. Curr Opin Lipidol 13(2):155-164

Koh WP, Yuan JM, Van Den Berg D, Lee HP, Yu MC (2004) Interaction between cyclooxygenase- 2 gene polymorphism and dietary n-6 polyunsaturated fatty acids on colon cancer risk: the Singapore Chinese health study. Br J Cancer 90:1760-1764

Larsson SC, Kumlin M, Ingelman-Sundberg M, Wolk A (2004) Dietary long-chain n-3 fatty acids for the prevention of cancer: a review of potential mechanisms. Am J Clin Nutr 79(6):935-945

Lee TH, Hoover RL, Williams JD, Sperling RI, Ravalese J III, Spur BW, Robinson DR, Corey EJ, Lewis RA, Austen KF (1985) Effect of dietary enrichment with eicosapentaenoic and docosahexaenoic acids on in vitro neutrophil and monocyte leukotriene generation and neutrophil function. N Engl J Med 312(19): 1217-1224. doi:10.1056/NEJM198505093121903

Lee CR, Bottone FG Jr, Krahn JM, Li L, Mohrenweiser HW, Cook ME, Petrovich RM, Bell DA, Eling TE, Zeldin DC (2007) Identification and functional characterization of polymorphisms in human cyclooxygenase-1 (PTGS1). Pharmacogenet Genomics 17(2):145-160. doi:10.1097/01.fpc.0000236340.87540.e3

Norat T, Bingham S, Ferrari P, Slimani N, Jenab M, Mazuir M, Overvad K, Olsen A, Tjonneland A, Clavel F, Boutron-Ruault MC, Kesse E, Boeing H, Bergmann MM, Nieters A, Linseisen J, Trichopoulou A, Trichopoulos D, Tountas Y, Berrino F, Palli D, Panico S, Tumino R, Vineis P, Bueno-de-Mesquita HB, Peeters PH, Engeset D, Lund E, Skeie G, Ardanaz E, Gonzalez C, Navarro C, Quiros JR, Sanchez MJ, Berglund G, Mattisson I, Hallmans G, Palmqvist R, Day NE, Khaw KT, Key TJ, San Joaquin M, Hemon B, Saracci R, Kaaks R, Riboli E (2005) Meat, fish, and colorectal cancer risk: the European prospective investigation into cancer and nutrition. J Natl Cancer Inst 97(12): 906-916. doi:10.1093/jnci/dji164

Poole EM, Bigler J, Whitton J, Sibert JG, Potter JD, Ulrich CM (2006) Prostacyclin synthase and arachidonate 5-lipoxygenase polymorphisms and risk of colorectal polyps. Cancer Epidemiol Biomarkers Prev 15(3):502-508

Poole EM, Bigler J, Whitton J, Sibert JG, Kulmacz RJ, Potter JD, Ulrich CM (2007) Genetic variability in prostaglandin synthesis, fish intake and risk of colorectal polyps. Carcinogenesis 28(6):1259-1263. doi:10.1093/carcin/bgm026

Pot GK, Geelen A, van Heijningen EM, Siezen CL, van Kranen HJ, Kampman E (2008) Opposing associations of serum n-3 and n-6 polyunsaturated fatty acids with colorectal adenoma risk: an endoscopy-based case-control study. Int J Cancer 123(8):19741977. doi:10.1002/ijc.23729

Reddy BS, Maeura Y (1984) Tumor promotion by dietary fat in azoxymethane-induced colon carcinogenesis in female F344 rats: influence of amount and source of dietary fat. J Natl Cancer Inst 72(3):745-750 
Sayers I, Barton S, Rorke S, Sawyer J, Peng Q, Beghe B, Ye S, Keith T, Clough JB, Holloway JW, Sampson AP, Holgate ST (2003) Promoter polymorphism in the 5-lipoxygenase (ALOX5) and 5-lipoxygenase-activating protein (ALOX5AP) genes and asthma susceptibility in a Caucasian population. Clin Exp Allergy 33(8):1103-1110

Serhan CN (2005) Novel eicosanoid and docosanoid mediators: resolvins, docosatrienes, and neuroprotectins. Curr Opin Clin Nutr Metab Care 8(2):115-121

Serhan CN, Yacoubian S, Yang R (2008) Anti-inflammatory and proresolving lipid mediators. Annu Rev Pathol 3:279-312. doi: 10.1146/annurev.pathmechdis.3.121806.151409

Shapiro AC, Wu D, Meydani SN (1993) Eicosanoids derived from arachidonic and eicosapentaenoic acids inhibit $\mathrm{T}$ cell proliferative response. Prostaglandins 45(3):229-240

Siezen CL, van Leeuwen AI, Kram NR, Luken ME, van Kranen HJ, Kampman E (2005) Colorectal adenoma risk is modified by the interplay between polymorphisms in arachidonic acid pathway genes and fish consumption. Carcinogenesis 26(2):449-457. doi: 10.1093/carcin/bgh336

Siezen CL, Bueno-de-Mesquita HB, Peeters PH, Kram NR, van Doeselaar M, van Kranen HJ (2006a) Polymorphisms in the genes involved in the arachidonic acid-pathway, fish consumption and the risk of colorectal cancer. Int J Cancer 119(2):297303. doi:10.1002/ijc. 21858

Siezen CL, Tijhuis MJ, Kram NR, van Soest EM, de Jong DJ, Fodde R, van Kranen HJ, Kampman E (2006b) Protective effect of nonsteroidal anti-inflammatory drugs on colorectal adenomas is modified by a polymorphism in peroxisome proliferator-activated receptor delta. Pharmacogenet Genomics 16(1):43-50

Slattery ML, Caan BJ, Duncan D, Berry TD, Coates A, Kerber R (1994a) A computerized diet history questionnaire for epidemiologic studies. J Am Diet Assoc 94(7):761-766

Slattery ML, Dyer A, Jacobs DR Jr, Hilner JE, Caan BJ, Bild DE, Liu K, McDonald A, Van Horn L, Hardin M (1994b) A comparison of two methods to ascertain dietary intake: the CARDIA Study. J Clin Epidemiol 47(7):701-711
Slattery ML, Edwards SL, Ma KN, Friedman GD, Potter JD (1997a) Physical activity and colon cancer: a public health perspective. Ann Epidemiol 7(2):137-145

Slattery ML, Potter J, Caan B, Edwards S, Coates A, Ma KN, Berry TD (1997b) Energy balance and colon cancer-beyond physical activity. Cancer Res 57(1):75-80

Slattery ML, Potter JD, Duncan DM, Berry TD (1997c) Dietary fats and colon cancer: assessment of risk associated with specific fatty acids. Int J Cancer 73(5):670-677

Slattery ML, Benson J, Ma KN, Schaffer D, Potter JD (2001) Transfatty acids and colon cancer. Nutr Cancer 39(2):170-175

Tan XL, Nieters A, Hoffmeister M, Beckmann L, Brenner H, ChangClaude J (2007) Genetic polymorphisms in TP53, nonsteroidal anti-inflammatory drugs and the risk of colorectal cancer: evidence for gene-environment interaction? Pharmacogenet Genomics 17(8):639-645. doi:10.1097/FPC.0b013e3280d5121c

Ulrich CM, Whitton J, Yu JH, Sibert J, Sparks R, Potter JD, Bigler J (2005) PTGS2 (COX-2) $-765 \mathrm{G}>\mathrm{C}$ promoter variant reduces risk of colorectal adenoma among nonusers of nonsteroidal antiinflammatory drugs. Cancer Epidemiol Biomarkers Prev 14(3): 616-619

Ulrich CM, Bigler J, Potter JD (2006) Non-steroidal anti-inflammatory drugs for cancer prevention: promise, perils and pharmacogenetics. Nat Rev Cancer 6(2):130-140. doi:10.1038/nrc1801

Wang YC, Kuo WH, Chen CY, Lin HY, Wu HT, Liu BH, Chen CH, Mersmann HJ, Chang KJ, Ding ST (2010) Docosahexaenoic acid regulates serum amyloid A protein to promote lipolysis through down regulation of perilipin. J Nutr Biochem 21(4):317-324. doi:10.1016/j.jnutbio.2009.01.004

WCRF, AICR (2007) Food, nutrition, physical activity, and the prevention of cancer: a global perpective. AICR, Washington, DC

Woutersen RA, Appel MJ, van Garderen-Hoetmer A, Wijnands MV (1999) Dietary fat and carcinogenesis. Mutat Res 443(1-2): $111-127$ 